\title{
Perennial ryegrass cultivars: herbage yield in multi-site plot trials
}

\author{
H.S. EASTON ${ }^{1}$, D.B. BAIRD ${ }^{2}$, N.E. CAMERON ${ }^{3}$, G.A. KERR ${ }^{4}$, M. NORRISS ${ }^{5}$ \\ and A.V. STEWART ${ }^{6}$ \\ ${ }^{1}$ AgResearch Grasslands, Private Bag 11008, Palmerston North \\ ${ }^{2}$ AgResearch, P.O. Box 60, Lincoln \\ ${ }^{3}$ Cropmark Seeds Ltd, P.O. Box 16574, Christchurch \\ ${ }^{4}$ Agriseeds, 2547 Old West Coast Rd, RD 1, Christchurch \\ ${ }^{5}$ Wrightson Research, P.O. Box 939, Christchurch \\ ${ }^{6}$ Pyne Gould Guinness, P.O. Box 3100, Christchurch \\ ${ }^{1}$ sydney.easton@agresearch.co.nz
}

\begin{abstract}
Perennial ryegrass (Lolium perenne) cultivars adapted to New Zealand conditions are bred by several scientifically equipped New Zealand interests. New cultivars are evaluated in a network of trials organised by the New Zealand Plant Breeding and Research Association. This paper presents data from 17 trials completed throughout New Zealand since 1991. Data were analysed for each trial and then in a multi-site analysis enabling comparison of estimated cultivar means, over all New Zealand trials, North Island trials and Canterbury trials.

New cultivars released to the market yielded on average $6 \%$ more herbage annually, and $9 \%$ in summer, than cultivars available before 1991. Other cultivars were evaluated but showed no yield advantage and have not been commercially released. Point analysis of plots in the final season of trials indicated that recently released cultivars maintain ground cover at least as well as the older ones. Limited data for rust infection indicated that the oldest cultivars are the most severely affected.
\end{abstract}

Keywords: cultivar evaluation, endophyte, NZPBRA, pasture plant breeding, perennial ryegrass

\section{Introduction}

Perennial ryegrass (Lolium perenne) (PRG) is the major grass species in New Zealand's most fertile and highest producing pastures, and is the major dietary component of our most intensively farmed grazing livestock. It is characterised by ease of management, rapid recovery from grazing, adaptation to high soil fertility and good forage quality. PRG was introduced to New Zealand in the $19^{\text {th }}$ century, and large areas were sown after 1880 . The importance of PRG increased through the first half of the $20^{\text {th }}$ century, as soil fertility improved.
Active scientific improvement of PRG began in the 1920s (Levy \& Davies 1929) and the first certified strains of pedigree PRG were made available in the 1929-30 season. It was shown that the best seed lines available in New Zealand were superior in our environment to strains from overseas. Several different "types" were identified and described, and the elite type favoured at the time was dense with fine tillers. Without registering new names or strains, pedigree New Zealand PRG was progressively improved from 1936 to 1960, with each generation of elite plants fed into the base of the certification system.

Two major changes in the early 1970 s were the release of cultivars based on the more open erect Mangere ecotype (Armstrong 1977; Duder 1976) and the engagement of the private sector in ryegrass improvement. There are currently more than 20 cultivars of PRG and long-rotation hybrid ryegrass available in New Zealand, including a range of morphological type and date of reproductive maturity (Charlton \& Stewart 2000).

The New Zealand Plant Breeding and Research Association (NZPBRA) is an association of companies involved in the development and marketing of proprietary cultivars. The NZPBRA, in association with AgResearch, arranges an ongoing series of plot trials throughout New Zealand, to evaluate new cultivars before their entry into the market. These trials are conducted by personnel of member companies, or are contracted to other parties. An agreed protocol, with some flexibility, is followed to ensure the scientific soundness of the results. This paper reports the results of 17 trials of experimental cultivars of PRG and longrotation hybrid ryegrass, established between 1991 and 1996. Results for one of the trials have been presented elsewhere (Thom et al. 1998). Trials for Italian ryegrass were presented previously (Easton $e t$ al. 1997).

\section{Materials and methods}

Seventeen trials were established at ten different sites (Table 1). 
Table 1 Establishment date, location, number of perennial ryegrass cultivars and management of each trial.

\begin{tabular}{|c|c|c|c|c|}
\hline $\begin{array}{l}\text { Establishment } \\
\text { date }\end{array}$ & Location & $\begin{array}{l}\text { Number of } \\
\text { cultivars }\end{array}$ & $\begin{array}{l}\text { Management } \\
\text { Mixed/pure }\end{array}$ & Defoliation \\
\hline 1991 & Normanby, Taranaki & 13 & with clover & grazed, cattle \\
\hline 1991 & Aorangi Farm, Manawatu & 13 & with clover & grazed, sheep \\
\hline 1991 & Courtenay, Canterbury* & 14 & with clover & grazed, sheep \\
\hline 1991 & Lincoln, Canterbury & 14 & pure grass & grazed, sheep \\
\hline 1992 & Ruakura, Waikato* & 16 & with clover & grazed, cattle \\
\hline 1992 & West Melton, Canterbury & 12 & pure grass & mown \\
\hline 1993 & Ruakura, Waikato* & 12 & pure grass & mown \\
\hline 1993 & Lincoln, Canterbury & 13 & pure grass & grazed, sheep \\
\hline 1994 & Normanby, Taranaki* & 7 & with clover & grazed, cattle \\
\hline 1994 & Palmerston N, Manawatu & 7 & pure grass & mown \\
\hline 1994 & West Melton, Canterbury & 7 & pure grass & mown \\
\hline 1994 & Gore, Southland & 16 & with clover & grazed, sheep \\
\hline 1995 & St Peters School, Waikato* & 16 & with clover & grazed, cattle \\
\hline 1995 & Prebbleton, Canterbury & 10 & pure grass & mown \\
\hline 1995 & West Melton, Canterbury & 11 & pure grass & mown \\
\hline 1996 & Palmerston N, Manawatu & 9 & with clover & grazed, sheep \\
\hline 1996 & Gore, Southland* & 11 & pure grass & mown \\
\hline
\end{tabular}

Trials were sown in the autumn and ran for 3 years, except for the trial sown in Taranaki in 1991 (finished after 2 years owing to severe Argentine stem weevil damage) and in Canterbury in 1991 (continued for 4 years). Sowing rates for all trials were adjusted for germination rates. Seed was supplied by the companies responsible for the respective cultivars. The level of infection with ryegrass endophyte was specified, and, for the seed lines reported here, was above $75 \%$. However, for one trial at Gore, several cultivars were deliberately submitted free of endophyte. Data for these endophyte-free seed lines were treated separately and are not included in the tables and figures. Soil tests were performed before the trials, with nutrient levels adjusted to levels of good farm practice, aiming to achieve $\mathrm{pH}$ no lower than 5.8 and Olsen $\mathrm{P}$ of at least 25 . Nitrogen was applied to pure grass trials, usually after each defoliation, to replace losses estimated at $3 \%$ of mean dry matter harvested. For trials sown with clover, $\mathrm{N}$ was added only if clover content was poor or if substantial herbage was removed in determining yield.

Defoliation was by mowing or grazing (Table 1), and occurred when mean dry matter reached between 1000 and $3000 \mathrm{~kg} / \mathrm{ha}$, except that defoliation at lower levels than this was sometimes necessary to prevent reseeding in late summer, and plots were never left more than 40 days without defoliation. At each defoliation, herbage dry matter was assessed, either by cutting to $3-4 \mathrm{~cm}$ and drying a sample, or by calibrated capacitance probe. For those trials which were not pure PRG, a sample was taken at each defoliation and analysed for botanical composition. The composition of pure grass trials was determined at any defoliation where non-sown components contributed more than $5 \%$ of yield, and was verified at least annually.

The most widely purchased cultivars were used as controls. Yatsyn 1 was included in all 17 trials as a control, and Embassy was included in 10 trials. Grasslands Nui was used as a control in eight earlier trials. Other cultivars were included as decided by the companies responsible for them. In all, 61 cultivars were present in one or more trials, including a few less persistent hybrids. This paper presents data for 21 cultivars present in four or more trials.

Herbage dry matter yield data (annual and seasonal) for each trial were analysed using Genstat, and then a multi-site analysis of variance of all sites was executed, also using Genstat. Sub-groups of trials according to region were then analysed to determine to what extent cultivar performance varied with region. Similarly, analyses were executed for sub-groups of trials according to management.

A regression analysis was applied to the data to estimate overall mean seasonal and annual yield for each cultivar, taking into account the overall means of the different trials in which the cultivar was present. This estimate is more precise for those cultivars present in a greater number of trials.

Point analysis data were collected at the end of 3 years for six of the trials, four of them mixed sward trials. A formal system of locating a given number of random points in a plot was applied, and each point was recorded for presence of ryegrass. The data, converted to a percentage, represent $\%$ ground cover. Multi-trial analysis was conducted and overall means estimated as for the herbage dry matter yield data. 
For some trials, visual notes were taken for infection with crown or stem rust (Puccinia coronata, $P$. graminis). However, there were not enough data for multi-site analysis.

\section{Results}

Mean total measured plot yield was just short of $15000 \mathrm{~kg} / \mathrm{ha}$ per annum, and for different trials ranged from 9000 to $21000 \mathrm{~kg} /$ ha per annum. In the mixed sward trials, the ryegrass component ranged from 61 to $81 \%$ of harvested dry matter (mean 73\%).

Significant differences between cultivars were recorded for seasonal and annual ryegrass yields in every trial. Coefficients of variation were generally below $10 \%$.

Cultivars, number of trials in which each was present and estimated mean seasonal and annual yields are presented in Table 2, and estimated annual means are presented again in Figure 1. Adjusted means were calculated independently for each season, and seasonal means do not add exactly to annual means. In all figures, the bar gives an $83 \%$ confidence interval, and two cultivars for which the bars do not overlap are significantly different at the $5 \%$ probability level. Bronsyn yielded particularly well in the five trials (plus one at Gore in which it was free of endophyte) in which it was present.

The mean annual yield of seven cultivars tested in these trials and released onto the market since 1993 (the first seven in Table 2 ) was $6 \%$ superior $(\mathrm{P}<0.01)$ to the mean of the seven cultivars available at the beginning of the period. In summer, this difference was $9 \%$. Conversely, the annual mean of another seven cultivars (coded in Table 2) tested in the trials but not released to the market was marginally inferior (3\%) to that of the established cultivars.

The interaction between cultivar yield and season was statistically significant, but cultivar yield between seasons was correlated. Summer and autumn yields were highly correlated $(\mathrm{r}=0.9, \mathrm{P}<0.0001)$, and these were both correlated with yields in spring $(r=0.7$, $\mathrm{P}<0.0001)$ and winter $(\mathrm{r}=0.5, \mathrm{P}=0.01)$. The correlation between spring and winter was not significant $(\mathrm{r}=0.14$, $\mathrm{P}=0.28$ ). Of the named cultivars, Bronsyn and Aries HD yielded relatively less well in winter than in other seasons, while Embassy and Vedette yielded relatively better. In spring, Impact yielded relatively less well than in other seasons, while Yatsyn 1 yielded relatively better. Otherwise, cultivars maintained their rankings across seasons (Table 3 ).

Combined analysis of sub-groups of trials indicated only minor specific adaptation to regions and none to
Table $\llbracket 2$ Perennial ryegrass cultivars, number of trials in which each was present and mean seasonal and annual adjusted yields $(\mathrm{kg} / \mathrm{ha})$ over all sites.

\begin{tabular}{|c|c|c|c|c|c|c|}
\hline \multirow{2}{*}{ Cultivar } & \multirow{2}{*}{$\begin{array}{l}\text { No of } \\
\text { trials }\end{array}$} & \multicolumn{5}{|c|}{---------------- Yield (kg/ha) ------------ } \\
\hline & & autumn & winter & spring & summer & annual \\
\hline es HD & 7 & 2900 & 1600 & 4700 & 4000 & 13300 \\
\hline ons & 6 & 3150 & 1600 & 4950 & 4325 & 14150 \\
\hline anno & 4 & 2825 & 1700 & 4700 & 3875 & 13150 \\
\hline bson & 4 & 2850 & 1650 & 4650 & 3800 & 13050 \\
\hline pact & 13 & 2900 & 1725 & 4375 & 4050 & 13100 \\
\hline ngston & 9 & 2625 & 1625 & 4550 & 3700 & 12600 \\
\hline amson & 12 & 2800 & 1600 & 4625 & 3850 & 13000 \\
\hline anks* & 8 & 2675 & 1650 & 4325 & 3575 & 12300 \\
\hline Embassy* & 10 & 2700 & 1700 & 4275 & 3550 & 12300 \\
\hline Marsden* & 5 & 2700 & 1575 & 4475 & 3675 & 12500 \\
\hline$u i^{*}$ & 8 & 2625 & 1550 & 4500 & 3575 & 12350 \\
\hline acific* & 6 & 2600 & 1525 & 4525 & 3475 & 12200 \\
\hline edette* & 8 & 2625 & 1725 & 4600 & 3600 & 12650 \\
\hline Yatsyn 1* & 17 & 2800 & 1600 & 4800 & 3775 & 13050 \\
\hline 5 & 8 & 2425 & 1600 & 4000 & 3400 & 11450 \\
\hline 9 & 4 & 2775 & 1700 & 4375 & 3750 & 12600 \\
\hline CSLP92 109 & 5 & 2725 & 1525 & 4650 & 3800 & 12800 \\
\hline NZA894 & 5 & 2800 & 1550 & 4425 & 3600 & 12450 \\
\hline NZA912 & 4 & 2825 & 1650 & 4425 & 3625 & 12600 \\
\hline G31 & 5 & 2275 & 1425 & 4075 & 3075 & 10900 \\
\hline PGGP2 & 4 & 2525 & 1400 & 4450 & 3350 & 11800 \\
\hline
\end{tabular}

* Cultivars released before 1994

Figure $\llbracket 1$ Estimated cultivar means over all 17 trials for annual herbage dry matter yield of perennial ryegrass cultivars certified for sale and present in at least four trials. Horizontal error bars give $83 \%$ confidence intervals. If bars do not overlap, cultivars are different at the $5 \%$ probability level.

All NZ trials Total

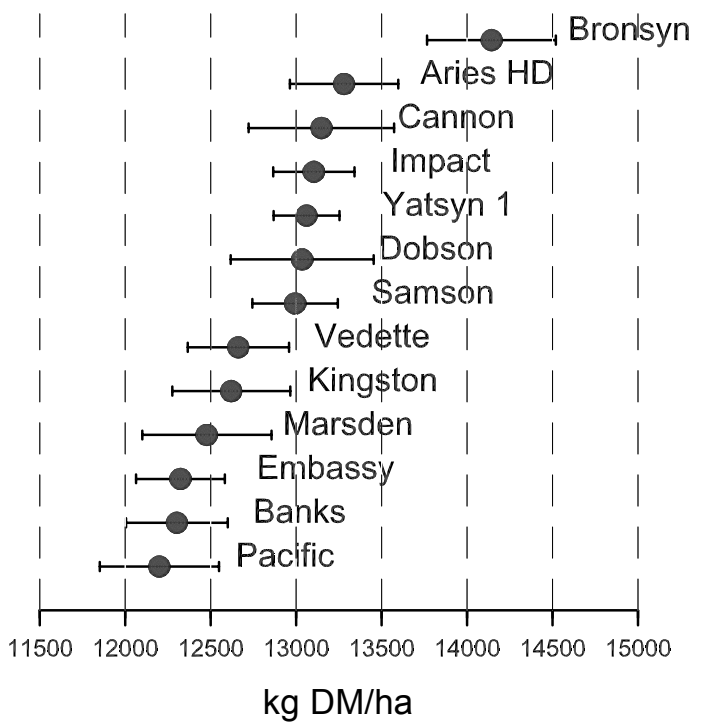


management regime or the presence of clover. Respective estimated cultivar mean yields for Canterbury and for the North Island were correlated $(\mathrm{r}=0.61, \mathrm{P}=0.0015)$. Of the named cultivars, Impact and Samson yielded relatively better in the North Island, while Banks yielded relatively better in Canterbury (Figure 2). Marsden and Kingston also yielded well in Canterbury, but were present in only two North Island trials. Aries HD, Bronsyn, Dobson and Marathon were each present in only one Canterbury trial. Since there were only two trials in Southland, it is not possible to determine whether relative performance there differs from other regions.

Relative performance over years was generally consistent, with the best cultivars in the first year continuing to yield well in the second and third years, reflected in high positive correlations between first and third year cultivar yields in almost all the trials (data not shown). Ryegrass ground cover data taken on 3 -year-old plots are presented in Figure 3. The oldest cultivar, Nui, and the two earlier flowering and more erect cultivars, Embassy and Banks, had lower mean $\%$ ground cover than the denser cultivars, but of the others, Pacific, ranked $8^{\text {th }}$, covered only a few $\%$ less ground than the highest ranked Impact, and the difference between them was barely significant at the $5 \%$ probability level. Ground cover data taken after 6 years in one Canterbury trial showed continuation of the same pattern (data not presented).
Table $₫ 3$ Seasonal rankings of perennial ryegrass cultivars for yield.

\begin{tabular}{lcccc}
\hline Cultivar & autumn & winter & spring & summer \\
\hline Aries HD & 2 & 13 & 4 & 3 \\
Bronsyn & 1 & 10 & 1 & 1 \\
Cannon & 5 & 5 & 3 & 4 \\
Dobson & 4 & 7 & 6 & 7 \\
Impact & 3 & 2 & 17 & 2 \\
Kingston & 15 & 9 & 9 & 10 \\
Samson & 7 & 10 & 7 & 5 \\
Banks & 14 & 8 & 18 & 15 \\
Embassy & 12 & 4 & 19 & 17 \\
Marsden & 13 & 15 & 12 & 11 \\
Nui & 17 & 16 & 11 & 16 \\
Pacific & 18 & 19 & 10 & 18 \\
Vedette & 16 & 1 & 8 & 14 \\
Yatsyn 1 & 8 & 12 & 2 & 8 \\
C5 & 20 & 14 & 21 & 19 \\
C9 & 10 & 3 & 16 & 9 \\
CSLP92 109 & 11 & 18 & 5 & 6 \\
NZA894 & 9 & 17 & 14 & 13 \\
NZA912 & 6 & 6 & 15 & 12 \\
PG31 & 21 & 20 & 20 & 21 \\
PGGP2 & 19 & 21 & 13 & 20 \\
\hline
\end{tabular}

Rust data for three trials are presented in Table 4. Only cultivars present in at least two trials noted for rust are included.

There were significant differences between ryegrass cultivars in some trials for the yield of associated white clover (white clover cultivar varied with the trial). For most of the mixed sward trials, there was a

Figure $\llbracket 2$ Estimated perennial ryegrass cultivar means for annual herbage dry matter yield for North Island and Canterbury trials. Horizontal error bars give $83 \%$ confidence intervals. If bars do not overlap, cultivars are different at the $5 \%$ probability level.

North Island trials Total

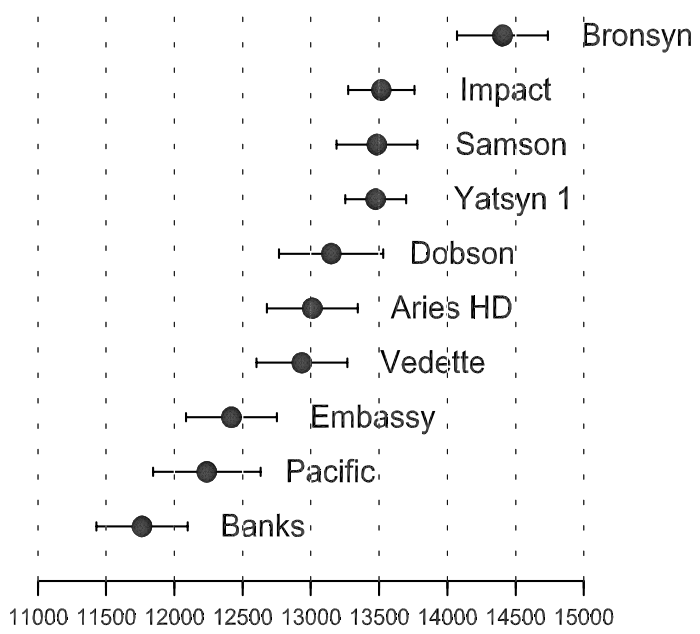

$\mathrm{kg} \mathrm{DM/ha}$

\section{Canterbury trials Total}

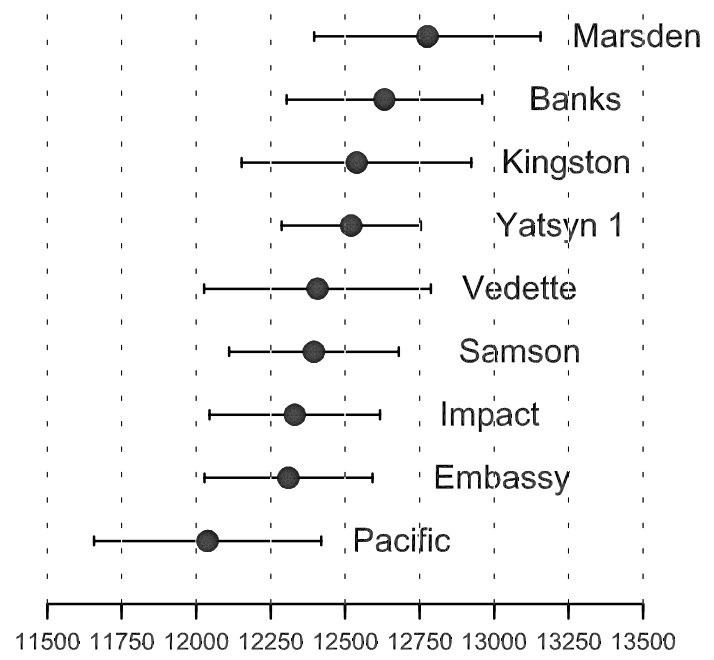

$\mathrm{kg} \mathrm{DM} / \mathrm{ha}$ 
highly significant negative correlation between ryegrass herbage yield and yield of the associated clover $(r<-$ 0.9 in three trials).

Figure $\llbracket 3$ Estimated overall cultivar means for ryegrass cover (\% of ground area), for perennial ryegrass cultivars certified for sale and present in at least four trials. Horizontal error bars give $83 \%$ confidence intervals. If bars do not overlap, cultivars are different at the $5 \%$ probability level.

Point Analysis Results

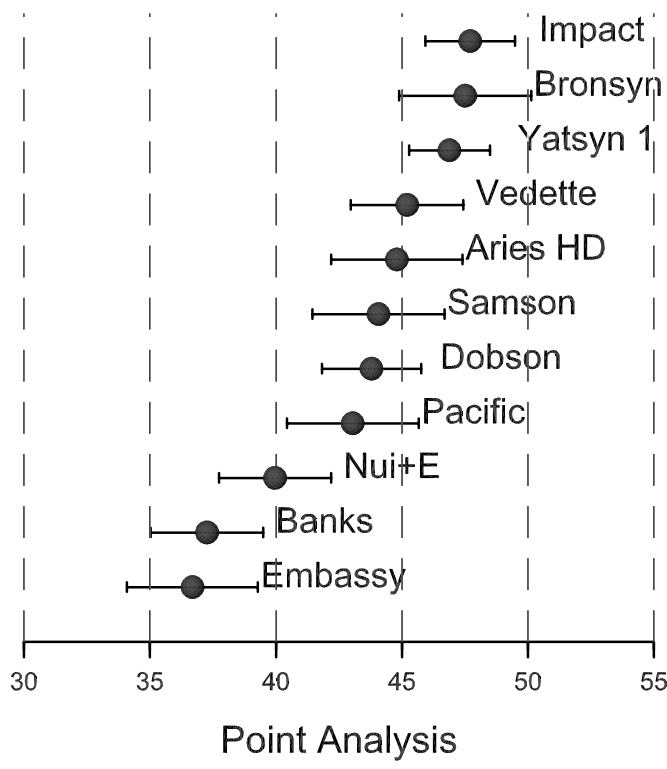

Table $\llbracket 4$ Visual notes for rust resistance of perennial ryegrass cultivars in three trials (means of 4 replicates per trial, 1 = severe infection, $9=$ freedom from rust).

\begin{tabular}{lccc}
\hline \multicolumn{3}{c}{ Site and year of establishment (Table 1) } \\
\hline Cultivar & Lincoln 1991 & Ruakura 1992 & Ruakura 1993 \\
Impact & 5.5 & 7.6 & 7 \\
Banks & 4.5 & 6.9 & 6 \\
Embassy & 4 & 6.4 & - \\
Nui & 1.5 & 3.8 & 2 \\
Pacific & 5.5 & 4.9 & - \\
Vedette & 5.5 & 5.9 & - \\
Yatsyn 1 & 3 & 5 & 3 \\
I.s.d. & 1.9 & 0.6 & 1.2 \\
\hline
\end{tabular}

\section{Discussion}

Ryegrass cultivars available in New Zealand have been through a rigorous testing system for herbage yield. The 17 trials from which data are presented cover most of the major climatic and soil-type zones of intensive pastoral farming in New Zealand. Only the Northland region could be said to be outside the range represented.
While trials allow comparison between PRG cultivars, they do not always accurately determine actual herbage yield. In particular, trials grazed by cattle and assessed by mowing may underestimate yield. For some trials, differences between cultivars were wide with the highest-yielding cultivar exceeding the mean by about $20 \%$ (37\% for one trial), and more than this in the summer. However, more typically, the highest yielding cultivar was about $10 \%$ above the mean. Further, the highest yielding cultivars were not always the same. The strength of the data presented here lies in the number of trials and sites involved, and in the multi-trial analysis which has enabled estimation of overall means for any cultivar present in four or more trials. Since some cultivars are present in many trials, and one in all of them, any cultivar present only in the higher yielding trials, for example, will have its estimated mean corrected for this factor, so that estimates for different cultivars can be properly compared, even if they were not in the same trials.

New cultivars released since 1991 produced on average more herbage than those available at the beginning of the trial period, particularly in summer when a mean $9 \%$ greater herbage yield was measured. Experimental cultivars that showed no advantage over the existing controls have not been released.

While the relative mean yield of some cultivars varied between Canterbury and the North Island (Figure 2), most yielded consistently, and there was no evidence of interaction with management or whether or not clover was present. For a farmer seeking information about a cultivar, mean yield over a number of trials is a more reliable indicator of productivity than the results of one trial, even if the one trial is close to the farmer's own property.

Variation between cultivars in response to crown rust has been reported previously (Easton et al. 1989). Rust strains evolve with time, so that cultivars which are resistant when released may lose their resistance in subsequent years. Rust data were not collected often enough to support a multi-site analysis. In some trials, only trivial rust was observed. Results from three trials (Table 4) show some consistent differences between cultivars. The oldest cultivars, Nui and Yatsyn 1, were consistently poor. At the time of its release, Nui was noted as resistant to rust (Armstrong 1977). Rust data have been collected more frequently from trials sown since 1996 (not yet complete), so that more information will be available in the future.

Variation between cultivars in the yield of the associated white clover was largely a function of competition, with less clover growing in the presence of the most vigorous PRG cultivars. Managing pasture to maintain good clover content in the presence of 
vigorous ryegrass is an essential element in gaining benefit from greater pasture yield.

There was no evidence to suggest that new cultivars persisted any less well than the older ones. Ground cover \% after 3 years (Figure 3 ) was as good for the newer cultivars as for the old, and third year cultivar yield was correlated with first.

Our data thus show that under rigorous evaluation, new cultivars yield on average more herbage than older controls over a wide range of environments, particularly in summer, and persist as well or better. The limited data available indicate ongoing improvement in rust resistance, and this is substantiated by data from other experiments not presented here. These results complement our earlier report of improvement in Italian ryegrass cultivars (Easton et al. 1997).

Ryegrass seed lines vary for other factors than the dry matter yield potential. Seed quality, endophyte infection levels, nature of the endophyte and its interaction with its host in producing bioactive compounds, flowering date and quality-related parameters such as digestibility and protein content may all vary. These factors will all affect pasture growth and the performance of grazing livestock, and all have implications for pasture management.

Farmers are not paid for herbage yield. New cultivars in themselves will not promote farm profitability. However, properly managed, they provide the basis for efficient and timely delivery of high quality livestock product.

\section{ACKNOWLEDGEMENTS}

The authors acknowledge the skill, commitment and professionalism of personnel who conducted the trials, in their own organisations and in Dexcel.

\section{REFERENCES}

Armstrong, C.S. 1977. 'Grasslands Nui' perennial ryegrass. New Zealand Journal of Experimental Agriculture 5: 381-384.

Charlton, J.F.L.; Stewart, A.V. 2000. Pasture and forage plants for New Zealand. Grassland Research and Practice Series 8: 7-15.

Duder, F.R. 1976. Analysis of variation in a local population of perennial ryegrass (Lolium perenne L.). Dissertation Dip.Agric.Sc, Massey University.

Easton, H.S. 1999. Endophyte in New Zealand ryegrass pastures, an overview. Ryegrass endophyte: an essential New Zealand symbiosis. Grassland Research and Practice Series 7: 1-9.

Easton, H.S.; Cooper, B.M.; Fraser, T.J.; Widdup, K.H. 1989. Crown rust on perennial ryegrass in field trials. Proceedings of the New Zealand Grassland Association 50: 253-254.

Easton, S.; Baird, D.; Baxter, G.; Cameron, N.; Hainsworth, R.; Johnston, C.; Kerr, G.; Lyons, T.; McCabe, R.; Nichol, W.; Norriss, M.; Stewart, A.; Thom, E. 1997. Annual and hybrid ryegrass cultivars in New Zealand. Proceedings of the New Zealand Grassland Association 59: 239-243.

Kerr, G.A. 1987. Evaluation of four perennial ryegrass cultivars in New Zealand. Proceedings of the New Zealand Grassland Association 48: 137-141.

Levy, E.B.; Davies, W.M. 1929. Strain investigation relative to grasses and clovers. New Zealand Journal of Agriculture 39: 1-8.

Thom, E.R.; Waugh, C.D.; McCabe, R.J. 1998. Growth and persistence of perennial and hybrid ryegrasses when grazed by dairy cows in the central Waikato region of New Zealand. New Zealand Journal of Agricultural Research 41: 477-486. 